\title{
Transitions from short to long-term outcomes in pediatric critical care: considerations for clinical practice
}

\author{
Debbie A. Long ${ }^{1,2}$, Ericka L. Fink ${ }^{3,4} \wedge$ \\ ${ }^{1}$ School of Nursing, Centre for Healthcare Transformation, Queensland University of Technology, Brisbane, Queensland, Australia; ${ }^{2}$ Pediatric \\ Intensive Care Unit, Queensland Children's Hospital, Brisbane, Queensland, Australia; ${ }^{3}$ Division of Pediatric Critical Care Medicine, UPMC \\ Children's Hospital of Pittsburgh, Pittsburgh, PA, USA; ${ }^{4}$ Safar Center for Resuscitation Research, University of Pittsburgh, Pittsburgh, PA, USA \\ Contributions: (I) Conception and design: Both authors; (II) Administrative support: None; (III) Provision of study materials or patients: None; (IV) \\ Collection and assembly of data: None; (V) Data analysis and interpretation: None; (VI) Manuscript writing: Both authors; (VII) Final approval of \\ manuscript: Both authors. \\ Correspondence to: Ericka L. Fink, MD, MS. Division of Pediatric Critical Care Medicine, UPMC Children's Hospital of Pittsburgh, 4401 Penn \\ Avenue, Faculty Pavilion, 2nd floor, Pittsburgh, PA 15224, USA. Email: finkel@ccm.upmc.edu.
}

\begin{abstract}
Most children are surviving critical illness in highly resourced pediatric intensive care units (PICUs). However, in research studies, many of these children survive with multi-domain health sequelae that has the potential to affect development over many years, termed post-intensive care syndrome-pediatrics (PICS-p). Clinically, there are no recommendations for the assessment and follow-up of children with critical illness as exists for the premature neonatal and congenital heart disease populations. In research studies, primary and secondary outcomes are largely assessed at or prior to hospital discharge, disregarding post-hospital outcomes important to PICU stakeholders. Incorporating longer term outcomes into clinical and research programs, however, can no longer be overlooked. Barriers to outcomes assessments are varied and generalized vs. individualized, but some PICU centers are discovering how to overcome them and are providing this service to families_-sometimes specific populations_-in need. Research programs and funders are increasingly recognizing the value and need to assess long-term outcomes post-PICU. Finally, we should seek the strong backing of the PICU community and families to insist that long-term outcomes become our new clinical standard of care. PICUs should consider development of a multicenter, multinational collaborative to assess clinical outcomes and optimize care delivery and patient and family outcomes. The aim of this review is to present the potential considerations of implementing long-term clinical follow-up following pediatric critical illness.
\end{abstract}

Keywords: Child; critical care; outcome assessment; post intensive care syndrome; family

Submitted Feb 08, 2021. Accepted for publication Aug 09, 2021.

doi: $10.21037 / \mathrm{tp}-21-61$

View this article at: https://dx.doi.org/10.21037/tp-21-61

\section{Introduction}

The traditional goal of intensive care has been to prevent death. Contemporary pediatric intensive care units (PICU) now report low mortality rates (2-4\%) (1). Declining mortality rates have led to a new health care need: an increasing number of children who have survived pediatric critical illness but with incomplete functional and neurodevelopmental recovery. Many studies report that PICU survivors experience from a broad range of physical (2,3), cognitive (4-6), emotional $(7,8)$, and social problems (9) along with adverse healthrelated quality of life (HRQoL) (10-15). These adverse outcomes are unique and can be experienced both alone or in combination by children and families (16-18). The impact

\footnotetext{
$\wedge$ ORCID: 0000-0002-3683-4571.
} 


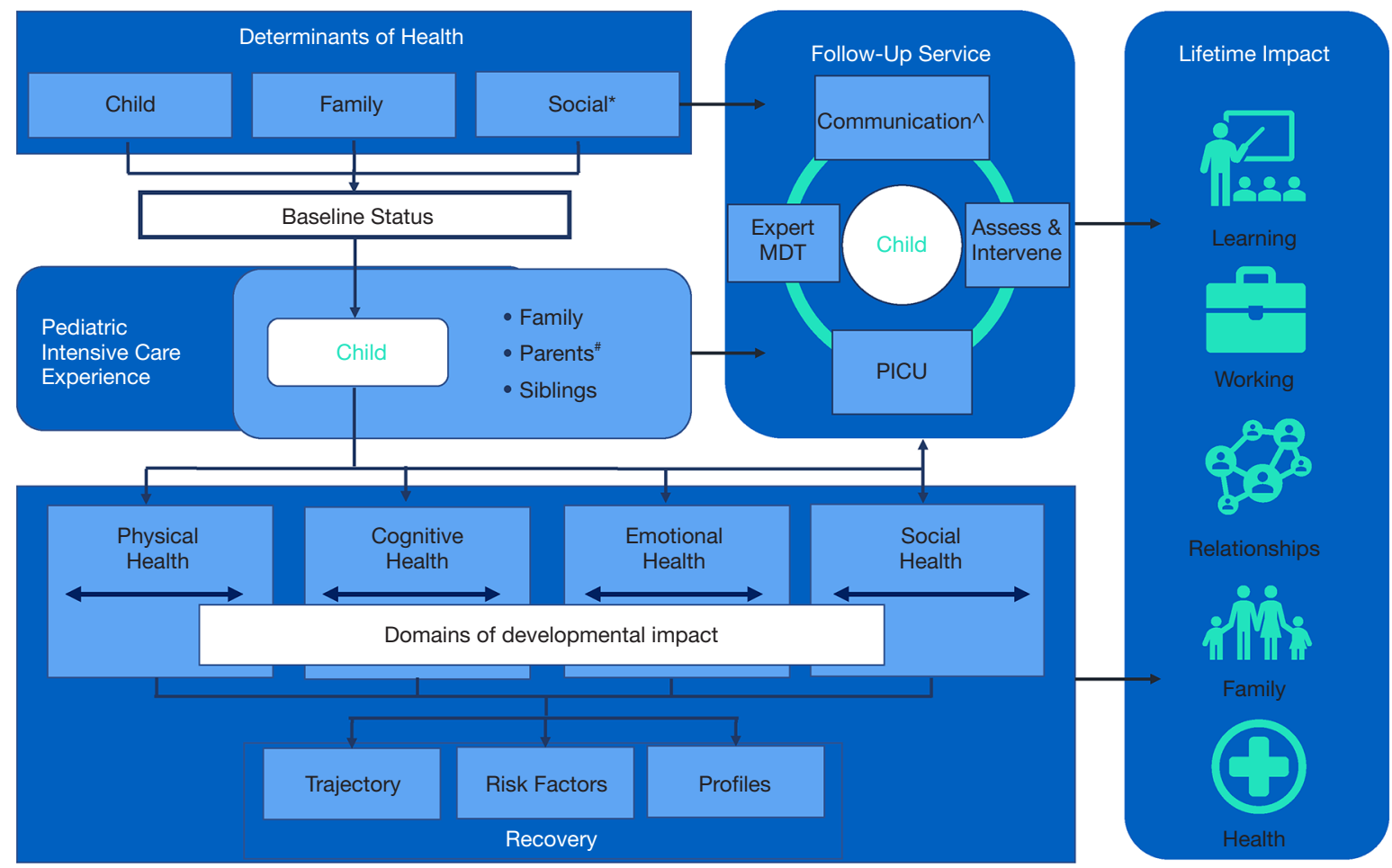

Figure 1 Modified Post-Intensive Care Syndrome - pediatrics (PICS-p) framework. Adapted with permission Wolters Kluwer Health, Inc.: Manning et al., 2018, Pediatric Critical Care Medicine (21). *, social determinants of health include concepts such as poverty, access to healthcare and community services, food security, neighborhood and environment, housing, and access to education. *, parents

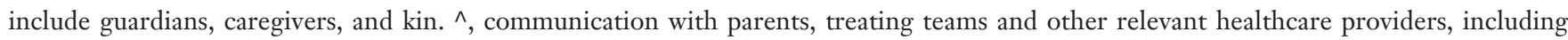
pediatricians, general practitioners, and allied health professionals currently providing care for child. MDT, multidisciplinary team.

and trajectory of these outcomes are experienced individually and can synergistically affect development, school and work performance, family functioning, and relationships (19-21). Further, children in ICU are exposed to various interventions, but these lifesaving support interventions are now implicated in their contribution to poorer outcomes (10). Altogether, this constellation of issues is also called post intensive care syndrome in pediatrics (PICS-p), which can last for months or years (22). The PICS-p framework proposes the premorbid child and sociodemographic factors which could contribute to the development of poorer outcomes and the interdependence of the child and family when considering the impact. These, in combination with many other factors, will have a profound impact on subsequent recovery (Figure 1). While the factors contributing to PICS-p are still to be fully understood, they are generally considered to be a combination of child and parent characteristics, pre-morbid health and development status, severity of critical illness, PICU treatment, and post-PICU factors $(23,24)$.
Interventions to prevent and treat psychological effects of pediatric critical illness to minimize impairment are being studied but much more is needed $(20,25)$. Further, historically, most pediatric critical care randomized trials only measure acute and short-term outcomes, such as organ dysfunction, ventilator free days and PICU length of stay as the primary outcomes of interest, with long-term outcomes after hospital discharge only seen as secondary or safety signals (26-29). This approach is insufficient however, to determine the lasting impact of interventions across the continuum of care for the pediatric critically ill population, which becomes a key issue as survivorship increases (30).

Routine, long-term outcomes assessment of pediatric critical care survivors would assist to fill knowledge gaps in PICS-p prevalence and patient and clinical risk factors associated with new impairment. In due course, these data can assist in developing hypotheses for further interventions to improve long-term outcomes. Ultimately, as a marker of quality care, these data can inform benchmarking, not only 


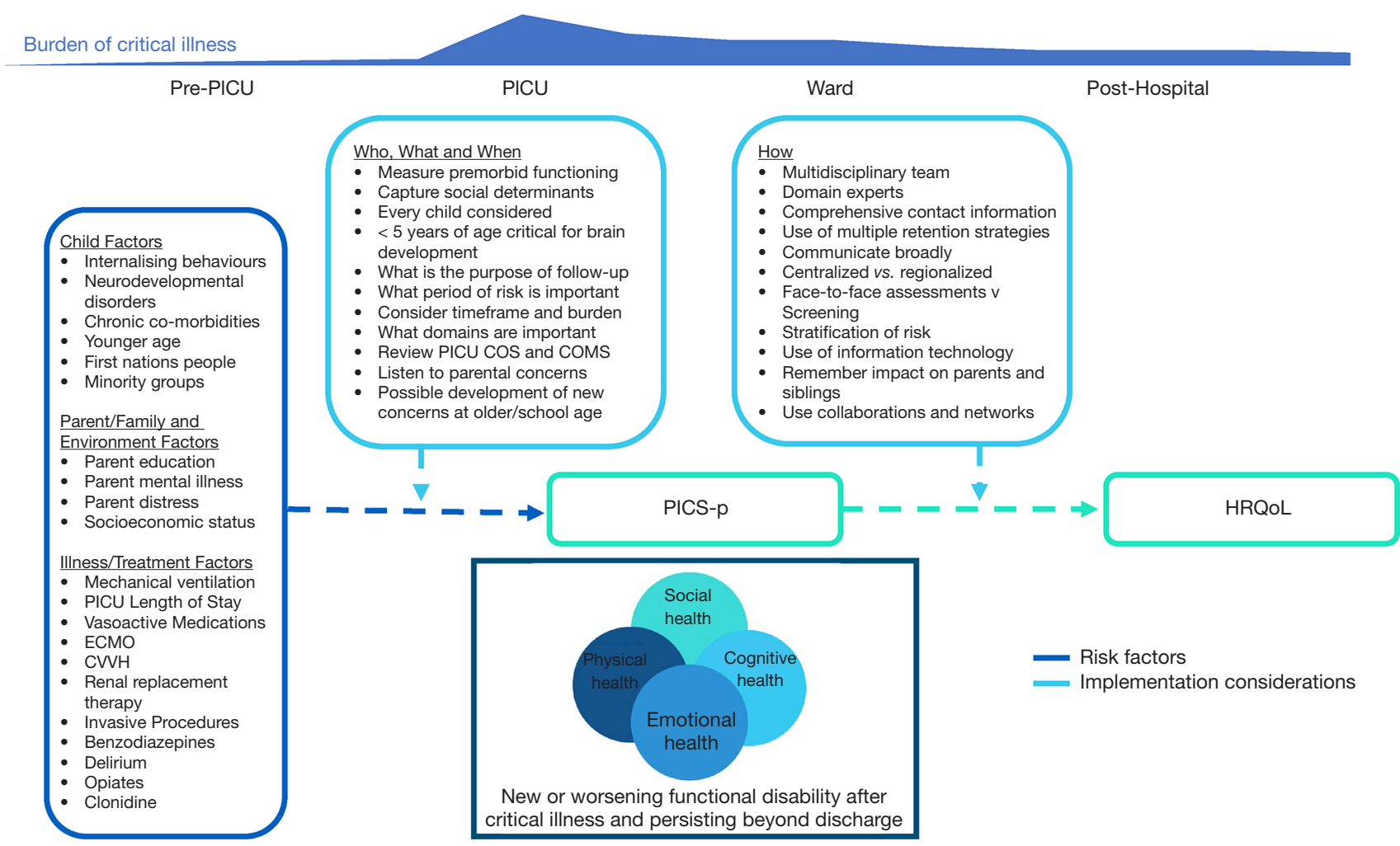

Figure 2 Considerations for implementing PICU Follow-Up. Adapted from Pavoni et al., 2020, ICU Management \& Practice (34). ECMO, extracorporeal membrane oxygenation; CVVH, Central Veno-Venous Haemofiltration; COS, Core Outcome Set; COMS, Core Outcome Measure Set; PICS-p, Post Intensive Care Syndrome-pediatrics; HRQoL, Health Related Quality of Life.

locally, but also regionally and globally (31). The reason for measuring long-term outcomes in the clinical context are varied, but equally important (32). Ideally, each child and family's recovery plan are personalized and optimized based on longitudinal, coordinated assessment. This can provide ongoing data to families and care providerscritical and primary care among others-and ensures that that child's best interests are paramount. Importantly, assessment of long-term outcomes can provide vital and accurate information to parents and clinicians to inform clinical decision making or redirection of care, advocate for additional rehabilitative treatment and resources, and provide a comprehensive resource for other care providers and educators around areas of vulnerability. In order to help identify improvements in both the quality of treatment and outcomes of care, as well as being able to identify those at highest risk for monitoring and intervention, our goal now is to appreciate that intensive care does not stop on discharge from the PICU and that survivors require ongoing monitoring and care to ensure optimal recovery (33) (see Figure 2). This goal is now being reflected in recent pediatric literature, which has prioritized assessing long-term outcomes for both research and clinical practice (35-39).

As the importance of assessing long-term outcomes become more recognized, and evidence helps to raise awareness and garner support, how do we begin to introduce the assessment of long-term outcomes into the care we provide? In viewing long-term outcome assessment through a "complex intervention" lens (40), this commentary paper outlines some important considerations for implementing the current evidence and understanding on PICS-p and long-term outcomes into practice. We define 'follow-up' to be any form of follow-up care provided after a PICU discharge and includes clinics and non-traditional settings.

\section{Who should be followed up?}

While it would make sense to prioritize the child when considering who should be followed up, evidence strongly supports also following up parents and families. It is 
well established that child developmental outcomes are influenced by a complex interplay of multiple factors including parental and family circumstances and the environment they are being discharged into, having more of an influence on outcome than just illness/injury and treatment factors alone $(41,42)$. Therefore, every child should ideally be evaluated as a candidate for long-term follow-up based their individual circumstances, rather than just a period of time they received mechanical ventilation or a diagnostic group. Unfortunately, many services will not have the financial or human resources to follow-up every child. Therefore, consideration of several risk factors for poorer outcomes should be considered.

\section{Child factors}

Many studies to date have been retrospective or observational and lacked assessment of pre-morbid or baseline functioning or other child characteristics. However, several child factors have been identified that contribute to poorer outcome. Le Brocque et al. found that child internalizing behaviors (e.g., shy, withdrawn, prefers to be alone) were a risk factor for the development of elevated post-PICU post-traumatic stress symptoms (PTSS), in particular membership to the chronic PTSS trajectory (6). Similar to other cohorts [e.g., congenital heart disease (CHD)], the presence of premorbid impairment and chronic co-morbidities are more prevalent in the PICU cohort and subsequently make them more susceptible to the impact of critical illness on development and behavior (7,43-48). Furthermore, these risk factors have been independently linked to child outcome in general pediatric cohorts, regardless of critical illness (49-51). In a systematic review on functional outcomes and physical impairments in PICU survivors, Ong et al. found younger age to be a significant risk factor for sequelae (52). Recently, however, Meert et al. found that younger age ( $<2$ years) was associated with better physical HRQoL in a communityacquired sepsis cohort (53). Furthermore, the THAPCA trial of out-of-hospital cardiac arrest (OOH-CA) survivors found that declines in neurobehavioral functioning were greatest in older children, and higher baseline functioning was predictive of greater decline at 12 months followup (54). These differences may represent the inclusion of the youngest infants in more recent studies, possibly highlighting less resilience in the youngest and oldest of children, or lack of developmentally expected improvement in pre-schoolers (55). First nations people and racial or ethnic minority groups have also been described as having poorer outcomes post-ICU, including mortality, chronic disease and neurodevelopment (56-63). It is important to consider that these outcomes in first nations and minority groups are often related to other global issues, such remoteness or isolation, access difficulties, and healthcare inequities, and these must be taken carefully into account when designing and developing follow-up care and services.

\section{Parent/family factors}

Maternal education $(16,64,65)$ and mental illness $(16,66,67)$ have repeatedly been identified as risk factors for child development, in addition to low socioeconomic status $(16,68,69)$ and social support $(70,71)$. Cheung and colleagues report that up to $30 \%$ of families have at least one social determinant of health on admission to PICU, with half of these having multiple needs (72). In a systematic review of risk factors for poor cognitive outcomes, Kachmar et al. found that lower socioeconomic status was independently associated with poorer cognitive outcomes in PICU survivors (73). It is proposed that social disadvantage may expose children to poor health prevention strategies, delays in recognition of deterioration, limited access to healthcare, and less support for their recovery and development post PICU $(74,75)$.

Maternal acute distress significantly predicts child PTSS, particularly chronic symptom trajectories that extend beyond 12 months post PICU (6). Additionally, Judge et al. reported that maternal PTSS levels were correlated with child behaviour up to 12 months post PICU admission (76). Longitudinal data from fathers remains scarce, however reports have shown paternal rates of post-traumatic stress disorder (PTSD) to be lower than maternal PTSD at 12 months $(77,78)$, which is argued to be the result of the predominantly maternal role of caregiving and subsequent differing perceptions of how life threatening the child's illness is $(78,79)$. Whether it is acute or long-term, there is a clear link between child and parent psychosocial outcome, which needs awareness and recognition from PICU admission to beyond discharge (4). Whilst child and parent/family factors are often not modifiable, understanding of these factors are important for accurate identification of those at risk and where and how support following intensive care could be provided.

\section{Illness and treatment factors}

Several studies have identified illness and PICU treatment 
factors that have been associated with poorer long-term outcomes in children. Watson et al. reports of a history of prematurity and cancer, in addition to exacerbations of chronic disease, as risk factors for decline in functional status at 6 months in a cohort of children with respiratory failure (80). Trauma and primary neurologic diagnoses have also been identified as risk factors for acquiring functional and cognitive disability (5). Of particular note, treatment risk factors are often seen as the most modifiable, therefore clinical trials in this area will potentially have the most impact. Invasive mechanical ventilation and prolonged PICU length of stay have been identified as independent risk factors for poor long-term functioning $(5,11,81)$. However, as Woodruff and Choong comment, it is difficult to separate illness and treatment factors, as intensity and duration of therapies is related to illness severity (15). Other treatments include vasoactive medications (11), extracorporeal membrane oxygenation (ECMO) (5), renal replacement therapy (5), and cardiopulmonary resuscitation (5), again reflecting an increased severity of illness. Additionally, tight glycemic control and withholding parental nutrition in the first week of PICU admission was associated with improved executive functioning, in particular inhibitory control up to 4 years following PICU admission (82-84).

Rennick further identified invasive procedures as a risk factor for the development of child PTSS (85). Benzodiazepines have been increasingly recognized as a risk factor for adverse outcomes in children. Several studies have highlighted benzodiazepines as a risk factor for the development of delirium (86-90). Although it is difficult to disentangle delirium as a causal factor in subsequent adverse outcomes, or as an artefact of illness severity, pediatric delirium has been recently linked to cognitive decline (89), PTSD (91) and poor HRQoL $(91,92)$. Use of benzodiazepines have been long associated with symptoms of PTSD, depression, anxiety and cognitive dysfunction in adult ICU patients $(93,94)$. A recent investigation in 265 children aged 2-18 found midazolam use was a significant predictor of acute PTSS symptoms (95). Whilst these PTSS symptoms were within 1 month of discharge and largely these symptoms may resolve, the development of PTSS at any timepoint could be seen as a gateway disorder to the development of other psychosocial impairments and healthcare avoidance or compliance $(96,97)$. The administration of opioids has had more of a mixed result. van Zellem et al. found the use of opioids was significantly associated with poorer neurodevelopmental outcome, independent of severity of illness, in meningococcal septic shock survivors (28). This finding has also recently been reported in extremely low birth weight infants, which found that cumulative exposure to opiates in the NICU was associated with worse cognitive scores at 2 years of age (98). Watson et al. found that administration of clonidine was significantly associated with decline in functional status, and methadone significantly associated with a reduction in HRQoL at 6 months in children with respiratory failure (80). Still, other studies have found no evidence of association between dose and duration of sedatives and opioids and adverse neurodevelopmental outcomes $(99,100)$. O'Meara AM et al. recently explored an animal model of repetitive benzodiazepine and opiate exposure in juvenile rats, simulating PICU-typical sedation, and demonstrated effects on multiple markers of brain development and plasticity (101). Importantly, this study highlighted that sedation and analgesia may create vulnerabilities that accumulate over time or manifest under stress or stimulus. Subtlety and latency may therefore explain the mixed results of neurotoxicity. Further understanding of PICU therapies is a necessary step in developing child-based and disease-based neuroprotective strategies for optimizing outcomes.

\section{What ages are important?}

Due to the heterogenous nature of the pediatric population, many different ages are represented across the developmental spectrum. Historically, research has been limited to school age children, due to the lack of valid and reliable assessments for infants and young children. The last few years have seen a progression in research across younger ages, better reflecting the typical PICU population. In addition, there is a growing understanding that between birth and 5 years of age is a period of significant brain development and that early life stressors, including critical illness, are significant risk factors for poor physical and mental health outcomes later in life (102). From a clinical and research perspective, the age in which children are followed up post PICU, and the duration of follow-up will depend on the: (I) purpose of the follow-up, (II) presumed period of risk, and (III) burden on long-term tracking (103). Additionally, certain domains may not be assessed until a particular age or there may not be well validated tools available to assess a domain (32). For example, executive functioning does not develop until later in early childhood and therefore the ability to assess this is difficult in a toddler. The advantage of school-aged assessments is that more domains can be assessed, along 
Table 1 PICU Core Outcome Set and PICU COS - Extended

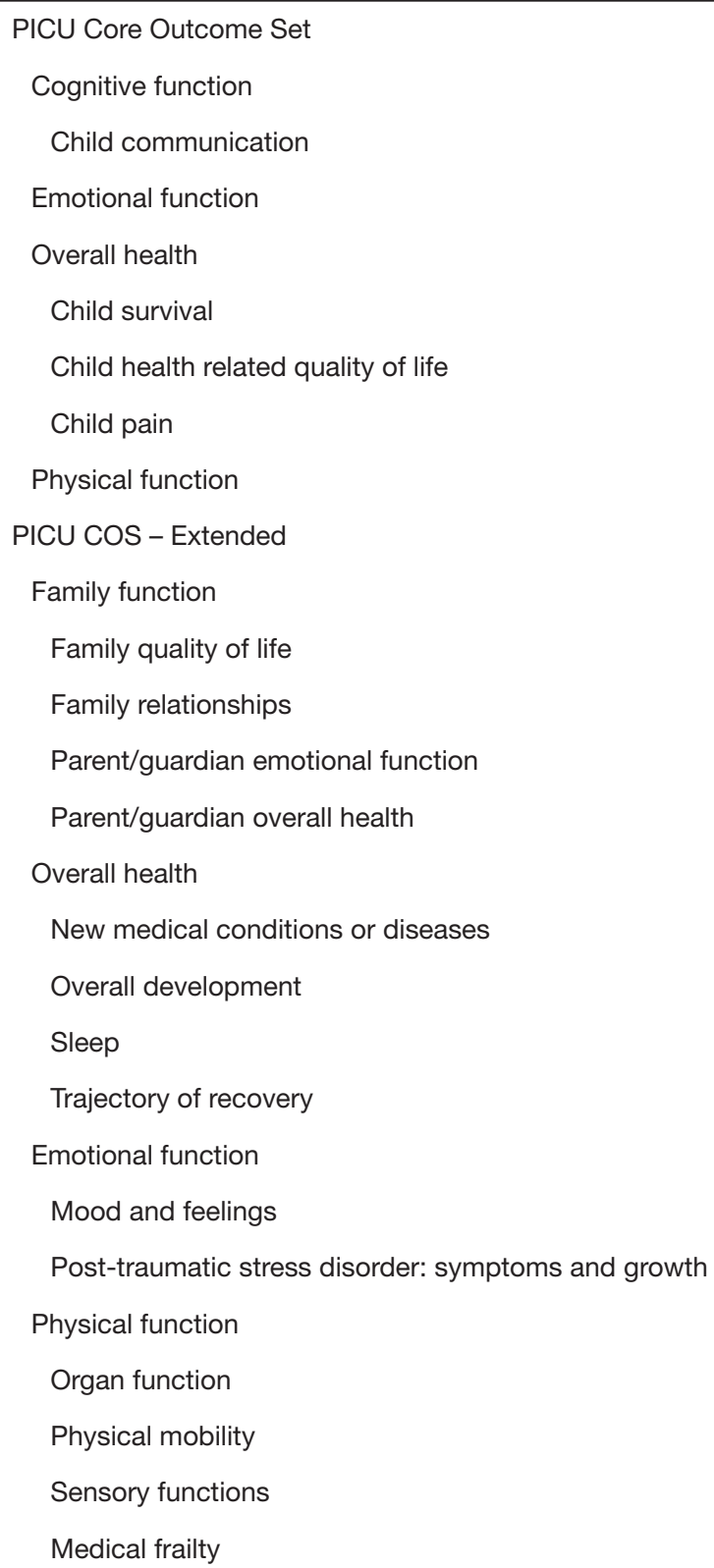

Used with permission from Wolters Kluwer Health, Inc.: Fink et al., [2020], Critical Care Medicine (31). PICU, pediatric intensive care unit; COS, Core Outcome Set.

with the availability of more assessment tools. Additionally, as children start developing literacy skills, the likelihood of relying on parent proxy reports becomes less likely, however the contribution of parent perception remains important. The recommended duration of surveillance for the PICU population requires prospective research to inform guidance, however infants and toddlers should likely undergo neurocognitive testing at school age.

\section{Most appropriate domains and assessments?}

Since the development of the PICS-p framework, there have been significant efforts in the international PICU community to address the limitations of heterogeneity of PICU long-term outcome methodology, populations, domains, and assessment tools. A scoping review undertaken by Maddux et al. identified 366 unique instruments across pediatric critical illness studies, with a median of 77 instruments for individual domains (104). Subsequent to this, a multinational, multi-stakeholder, Delphi consensus study was undertaken to establish a PICU Core Outcome Set (COS) for inclusion in clinical and research programs (31). The final COS recommended four global domains (cognitive, emotional, physical and overall health) and four specific outcomes (child HRQoL, pain, survival, and communication) (see Table 1). The COS also offers an important Extended COS, which includes domains which were ranked highly by family members but fell below the consensus threshold for inclusion in the main COS. The implementation of these domains and specific outcomes will be facilitated by the recommendation of feasible, reliable, age-appropriate and validated measurement instruments for each outcome; a task currently underway by the POST PICU investigators [Core Outcome Measures Set (COMS)]. Additionally, the PICU COS and COMS will offer a range of assessments that more comprehensively address a broad range of neurodevelopmental domains. Streamlining what we assess with the recommended PICU COS and COMS will ultimately provide huge insights and benefits to the PICU community by allowing for increased ability to compare outcomes across studies and populations and decrease the potential for reporting bias.

\section{What is the best format for follow-up?}

There is a debate ensuing about who is actually best placed to provide optimal post PICU care. Some wager that PICU clinicians would have familiarity with PICU interventions (and their complications) and that this would address fragmented care after PICU $(105,106)$. Others, acknowledging that impairments can span several domains, suggest that care needs to be provided by a multidisciplinary team with expertise in these domains, such as a rehabilitation medicine provider (107-110). Vijayaraghavan et al. suggests that the advent of specialized medicine stems 
from the recognition that medicine is too expansive for any one group to claim expertise over all domains (107). Certainly, it is true that a community of interdisciplinary experts are required for PICU survivors to recover and thrive. Partnerships with other healthcare professionals could also be explored, such as general practitioners (GPs) or pediatricians, as they are aptly placed to undertake routine child health screening but have less or no training in PICS-p (111-114). One study has demonstrated that a general pediatrician staffed developmental access clinic was able to decrease the time to evaluation of early childhood developmental disorders, where only $50 \%$ of children required a subsequent referral to a developmental behavioral pediatrician (115). The overarching local and national healthcare system will influence how the followup care is provided. In some countries, the family General Practitioner $(116,117)$ is the gatekeeper to child health and wellbeing, whereas in others the pediatrician provides this service, but knowledge of PICS-p is not widespread in this community $(118,119)$. A hybrid model is an alternate suggestion, whereby a shared care approach is used and both acute and primary care healthcare professionals provide input into the ongoing care of the child and family (120-122). Several studies have also provided evidence of non-inferiority of nurse-led pediatric care or shared care, particularly when bridging the gap between primary and secondary care (123-125).

Many other types of follow-up services have grappled with the provision of centralized versus regionalized care (109). We know that for families in rural, regional or remote areas, the centralization of acute PICU services can result in distance and time barriers to emergency care (126). However, research suggests that children have better outcomes when treated in pediatric focused facilities rather than general intensive care services $(127,128)$. How then should post PICU care be provided? One disadvantage of centralized clinics is the requirement to physically attend the clinic and families usually have to reside within a certain distance from the hospital. While the geographical spread of families from their hospitals in some countries might facilitate follow-up through a dedicated, centralized service, access and equity has proven to be quite difficult in other countries $(126,129)$. Many centralized services or clinics are developed on the premise of full face-to-face clinical assessments to provide detailed information and diagnostics. Unfortunately, these can often take hours and could be quite tiresome for young children and can be difficult to attend for families given other responsibilities. The method of surveillance screening, while quicker and cheaper, may not fully detect a child who really needs support.

The CHD neurodevelopmental follow-up statement suggests a tiered approach to these differences by stratifying low-risk children to receive surveillance screening and high-risk children to formal developmental evaluations (43). Should a low-risk child demonstrate any risk, they are then referred for formal developmental assessment. Should a high-risk child not be diagnosed with a developmental delay, then surveillance screening will continue. Periodic re-evaluation is also recommended at key milestone ages: 12-48 months, 3-5 years, and 11-12 years. Some neonatal follow-up programs offer a similar risk stratification format, however, propose several levels of referral (130). Children in these programs are assigned to 1 of 3 levels of follow-up: Level 1 (lowest risk)—standardized screening questionnaires mailed to families (e.g., parent completed screening questionnaire); Level 2 (moderate risk)—child assessed in interdisciplinary clinic (e.g., clinician completed neurodevelopmental examination and developmental screening); and, Level 3 (highest risk)—comprehensive assessment and referral to early intervention (e.g., face to face assessment with developmental specialist or psychologist). Pediatric oncology as a field has developed evidence-based guidelines and risk models to optimize follow-up eligibility, timing, and interventions for children with various types of cancer (131).

Several countries have invested significant efforts into ICU follow-up clinics to help support recovery following critical illness in adults (132-135). ICU follow-up clinics usually require the patient to attend the hospital to see a combination of interdisciplinary professionals, who assess progress in all PICS domains, provide medication therapy review, reconciliation and counselling, and coordinate care and communication with primary care providers and other specialists as needed. Prevedello and Preiser describe the structure of current adult follow-up clinics as nurse-led, physician led or multidisciplinary team-sharing responsibility (136). Despite these clinics developing since 1985 , they still vary greatly depending on the objective of the service, timing of consultations, interventions offered, and outcomes monitored (136).

Recently, Haines et al. shared clinicians' experience of ICU clinics and explored the enablers and barriers to successful implementation (137). Clinicians felt that ICU clinics were more successfully implemented when there was interprofessional teamwork, alignment and promotion of the clinic to organizational priorities and a humanizing of 
ICU survivorship. Barriers to successful implementation were lack of staff, identification of appropriate patients and subsequent limitations to accessing clinic, lack of funding, and practice variation between clinicians (137).

In the era of COVID-19, we have been forced to explore other methods to support ICU follow-up, consisting mostly of online services. Jalilian et al. comments that opportunities exist for multiple technologies to help extend healthcare delivery, reduce costs, improve the quality of care, and the patient experience (138). With advantages in health information technology, telemedicine, digital health and remote monitoring, there has been increasing investigations on the use of these technologies to facilitate patientclinician communication, track disease, intervene earlier for symptom management, and provide educational support to patients beyond the walls of the ICU and follow-up service. Such digital technologies could address some of the current barriers to ICU follow-up by, increasing accessibility, early recognition of impairment, reduction of hospital readmission, removal of financial and societal barriers to recovery, and understanding of the home environment (139). Alternatively, some families may lack access to internet resources needed for a secure telemedicine format. Telephone follow-up also remains a feasible method of contacting patients and families, particularly those who are difficult to assess due to remoteness or lack of other technologies (140-142).

Data on clinic cost-effectiveness are generally lacking; however, in adults with heart failure and chronic obstructive pulmonary disease, early follow-up improved healthcare utilization and mortality (143). Although the potential benefit of PICU follow-up clinics may be apparent to members of the field, robust data are needed to support their efficacy to obtain the necessary buy-in by hospital systems to invest in them. Adult post-ICU clinic providers remark that funding is their largest challenge to supporting their clinic, frequently relying on external funding such as charity donations (137). Follow-up services should routinely collect data to support their impact and ability to obtain funding, including attendance rates, patient/ family satisfaction, unmet needs and referrals, and adjusted patient and family centered outcomes and effect on health care utilization. Cost-effectiveness studies focused on these outcomes are critically needed.

Regardless of the format or program of PICU followup, the ideal health care model to optimize child recovery after critical illness should facilitate the transition of the child and family to the home environment and community, enable early recognition of complications during recovery, facilitate equity and access to appropriate healthcare services, and improve HRQoL (144). A model that tailors follow-up to meet the child's and family's individual needs is likely to be a more effective approach than the provision of multiple interventions in the event some deficits may develop (145).

\section{Supporting long-term follow-up and retention}

Many clinical and research reports describe challenges around retention of patients and families in longitudinal follow-up studies $(146,147)$. Systematic reviews and metaanalyses have shown that the number of unique trial retention strategies used in studies is correlated with higher retention rates $(146,148)$. The following strategies are recommended to maintain appropriate follow-up rates:

(I) Enrolment of patients and families prior to discharge from hospital and identification of a specific contact person (147);

(II) Multiple alternate email addresses and phone numbers of parents (146);

(III) Visits during intervening periods, for surveillance, and maintenance of family involvement with familiar staff even when the first formal study visit may be later (146);

(IV) Close communication with participants, including newsletters $(141,147,148)$;

(V) Close communication with, and mutual respect for, multiple health care providers of the patient (148);

(VI) Dedicated study personnel who can follow and call families at night and over weekends to accommodate parent work and family commitments (141,148);

(VII) Reimbursement or no outlay for transportation and parking and specific financial incentives for time spent the collection of study data $(141,148,149)$;

(VIII) Flexibility in data collection methods $(141,146)$;

(IX) Phone call or postcard reminders one month prior to data collection timepoint $(141,146,150)$.

Williams et al. suggests it is important to understand the reasons for non-response and loss to follow-up (144), as selection bias could result in study participants not representing the general ICU population. Suggested reasons for adult ICU patients not participating include being too well and wanting to resume their normal activities, not wanting to recall unpleasant memories, and being ill and not having the ability to respond. Important groups who do not participate in studies may have the most need for follow-up, and failure to receive follow-up 
is likely to suggest more positive results of ICU outcomes than reality. NICU follow-up challenges have further described living in rural areas and lower socioeconomic status as additional factors to consider with retention of participants (151). Reflections from a PICU follow-up trial in $\mathrm{OOH}-\mathrm{CA}$ survivors suggested that providing flexibility and convenience with follow-up times and methods, and optimizing relationships between the follow-up team and families also helped to maximize follow-up (141). Other important considerations are our vulnerable and chronically ill populations. Bonevski et al. suggests strengthening community partnerships when recruiting socially disadvantaged groups (152). Due to the ongoing nature of health requirements in chronically ill cohorts, Davies et al. comments never underestimate the amount of contacting required to engage participants, and how they respond is not always predictable (149). One follow-up clinic that focuses on pediatric neurocritical care patients had a $100 \%$ show rate in a report of their experience in administering the clinical program's first six months (110). The authors found that families were extremely satisfied with the program, which made referrals following neuropsychological testing in $81 \%$ of cases.

Finally, Wilcox and Ely highlight the importance of family in the recovery of ICU survivors, emphasizing the need to equally understand the needs and outcomes of essential social supports and networks (153). Importantly, these outcomes need to reflect those that are most important to the child and family, in addition to clinicians, researchers and other key stakeholders.

Maximizing follow-up with families also requires significant efforts around awareness and education in PICS-p. Whilst understanding of PICS-p has risen significantly, many parents and non-PICU healthcare workers remain unaware of adverse PICU outcomes. As a minimum, parents, healthcare professionals and early childhood educators need to be 'alert but not alarmed' and informed that a variety of issues can still arise at later stages. There are several strategies that can be employed to assist with awareness. Some PICUs now use videos or pamphlets to inform parents of PICS-p (anecdotal). Websites and social media are increasingly being used as a resource for patients and families, some incorporating blogs where survivors and family members can go for advice and community $(154,155)$. A further method of increasing awareness, particularly with clinicians, is through the use of discharge letters and summaries. These have been historically used to inform the ward staff, other treating clinicians, and general practitioners of the reason for admission, treatments, medications and required follow-up tests. These discharge summaries provide an opportunity to also discuss PICS-p and the child's particular risk factors $(156,157)$.

\section{Lessons learnt from other ICU experiences with long-term follow-up}

Several lessons can be taken from our neonatal, cardiac surgical, oncology and adult ICU colleagues' experience with follow-up thus far. Adult ICU guidelines recommend routine follow-up assessments immediately after discharge, with the interval between assessments extending as the time since ICU extends (158). This is particularly important for follow-up in childhood, for milestone attainment will slow as the child grows older. CHD guidelines go so far as providing age parameters based loosely around milestone attainment (43). Follow-up for ongoing or new morbidities will influence the timing of some assessments, over and above scheduled assessments. Pinto et al. demonstrated that the combined poor outcomes of new morbidity and mortality increased cumulatively over a 3 -year period post PICU (9.1\% to $20.8 \%$ ) (11), highlighting the need to constantly adjust assessments and timeframes. The question of how long to follow a child who is developing well and whose family is adjusting and coping appropriately will also depend on many circumstances. The NICU literature advises to consider milestone attainment, behavioral concerns, additional health problems requiring ongoing care, and family functioning prior to 'discharging' a child from specialist follow-up care (33). Whether further assessments at older ages are necessary could be decided on an individual basis and informed by screening during primary care visits or by family concerns (33). However, it should be acknowledged that many of the cognitive and academic problems that occur at school-age, particularly as academic demands become more intense and complex, will not be predicted by progress in the first few years of life $(159,160)$. Many high-risk children may not initially present to medical attention with obvious difficulties and remain undiagnosed and unassessed until they have failed in schoolwork and been bought to the attention of someone at an age that may be too late for effective intervention. These 'minor morbidities' are high prevalence, low severity and not disabling in the traditional sense, but have an additive effect to create significant functional challenges in school and social settings. Church et al. refers to the difficulty with 
prediction, challenges with identification, and the potential lack of awareness amongst parents, healthcare and education providers as a powerful combination of factors which are potentially preventable (161).

\section{Knowledge gaps and future directions}

In order to further translate the success of acute PICU care into long-term gains for our patients, there is more to achieve in understanding the long-term sequelae of our care and identifying the mechanisms to prevent or modify the risk of these sequelae. To date, the research describing these outcomes has been limited to specific medical conditions or age groups, thus not representing the general PICU cohort. Additionally, despite the PICS-p framework detailing multiple domains of impact, many studies have not assessed all identified outcomes simultaneously. This has the potential to misrepresent the complex interactions between multiple domains of vulnerability. A limitation of many studies to date has been the lack of baseline data. Future work should attempt to better characterize premorbid functioning so that the effects of illness and ICU-factors can be better isolated (162). Comparison with healthy community controls rather than population norms also allows for better control of confounding factors that may increase risks of both premorbid impairments and critical illness $(73,163)$, particularly as the timeframe since PICU admission increases.

Given the dynamic and complex state of child development, it will become increasingly important to assess long-term outcomes for extended periods, possibly until adulthood in particularly high-risk groups. This will enable us to truly appreciate any enduring effects on the patient, family, and society. An increasing number of follow-up time points will also allow trajectory analyses, helping us understand which domains are affected and when. Understanding trajectories of recovery will assist us in planning for the optimal timing of interventions to minimize or mitigate PICS-p. There are numerous studies and clinical services currently underway which are already addressing some of these gaps (164-172). The results of these and others, will only help to further our understanding and progress the care of children and their families following critical illness.

Future randomized controlled trials will be required to test alternate interventions to address modifiable risk factors and models of follow-up and health care. What this paradigm shift has enabled though, is an international community and network of PICU clinicians and researchers (e.g., PALISI POST-PICU Investigators, ANZICS PSG Long Term Outcome Group, Pediatric Neurocritical Care Research Group Outcomes subgroup, PICOLO Network) who are dedicated to pursuing the best possible outcomes for children and their families. The importance of these groups is in the standardization of study protocols, definitions and methodologies which will ultimately enable the collation of outcomes to answer the most important questions.

\section{Conclusions-a complex problem requiring a complex investment}

To date, research and the conceptualization of PICS-p remind us that there are complex biopsychosocial and developmental interfaces that can occur before, during, and after PICU and highlight the need for a more refined and tailored approach to both research and management. However, currently there is no standard PICU follow-up. Improving PICU outcomes is of socioeconomic importance and depends on recognizing PICS-p as an overarching term, which includes a variety of physical, cognitive, and emotional and social processes. For the PICU community, the challenge is not only to develop a detailed understanding of how we manage PICS-p but to discover what is effective, for which children, and in which circumstances, to deliver the best outcomes. Finally, PICUs seeking to develop and implement follow-up programs should incorporate resources developed by PICU stakeholders in their research programs. Serious consideration for the establishment of a multicenter, multinational collaborative clinical outcomes program should be taken as we can optimize our care through partnering with one another.

\section{Acknowledgments}

Funding: This work was supported by the National Institutes of Health [grant number NINDS R01 NS096714 to ELF].

\section{Footnote}

Provenance and Peer Review: This article was commissioned by the editorial office, Translational Pediatrics for the series "Pediatric Critical Care". The article has undergone external peer review.

Peer Review File: Available at https://dx.doi.org/10.21037/ tp-21-61 
Conflicts of Interest: Both authors have completed the ICMJE uniform disclosure form (available at https://dx.doi. org/10.21037/tp-21-61). The series "Pediatric Critical Care" was commissioned by the editorial office without any funding or sponsorship. DAL served as the unpaid Guest Editor of the series. ELF reports grant to the institution (NIH (NICHD) U10HD049983) before submission. This grant is complete at the time of publication. The other authors have no conflicts of interest to declare.

Ethical Statement: The authors are accountable for all aspects of the work in ensuring that questions related to the accuracy or integrity of any part of the work are appropriately investigated and resolved.

Open Access Statement: This is an Open Access article distributed in accordance with the Creative Commons Attribution-NonCommercial-NoDerivs 4.0 International License (CC BY-NC-ND 4.0), which permits the noncommercial replication and distribution of the article with the strict proviso that no changes or edits are made and the original work is properly cited (including links to both the formal publication through the relevant DOI and the license). See: https://creativecommons.org/licenses/by-nc-nd/4.0/.

\section{References}

1. ANZPIC Registry. Australian and New Zealand Paediatric Intensive Care Registry Annual Activity Report 20182020.

2. Knoester H, Bronner MB, Bos AP. Surviving pediatric intensive care: physical outcome after 3 months. Intensive Care Med 2008;34:1076-82.

3. Yang CF, Xue Y, Feng JY, et al. Gross motor developmental dysfunctional outcomes in infantile and toddler pediatric intensive care unit survivors. BMC Pediatr 2019;19:508.

4. Rees G, Gledhill J, Garralda ME, et al. Psychiatric outcome following paediatric intensive care unit (PICU) admission: a cohort study. Intensive Care Med 2004;30:1607-14.

5. Bone MF, Feinglass JM, Goodman DM. Risk factors for acquiring functional and cognitive disabilities during admission to a PICU*. Pediatr Crit Care Med 2014;15:640-8.

6. Le Brocque RM, Dow BL, McMahon H, et al. The Course of Posttraumatic Stress in Children: Examination of Symptom Trajectories and Predictive Factors Following Admission to Pediatric Intensive Care. Pediatr Crit Care Med 2020;21:e399-406.
7. Sobotka SA, Peters S, Pinto NP. Neurodevelopmental Disorders in the PICU Population. Clin Pediatr (Phila) 2018;57:913-9.

8. Rennick JE, Rashotte J. Psychological outcomes in children following pediatric intensive care unit hospitalization: a systematic review of the research. J Child Health Care 2009;13:128-49.

9. Kastner K, Pinto N, Msall ME, et al. PICU FollowUp: The Impact of Missed School in a Cohort of Children Following PICU Admission. Crit Care Explor 2019;1:e0033.

10. Shein SL, Slain KN, Clayton JA, et al. Neurologic and Functional Morbidity in Critically Ill Children With Bronchiolitis. Pediatr Crit Care Med 2017;18:1106-13.

11. Pinto NP, Rhinesmith EW, Kim TY, et al. Long-Term Function After Pediatric Critical Illness: Results From the Survivor Outcomes Study. Pediatr Crit Care Med 2017;18:e122-30.

12. Choong K, Fraser D, Al-Harbi S, et al. Functional Recovery in Critically Ill Children, the "WeeCover" Multicenter Study. Pediatr Crit Care Med 2018;19:145-54.

13. Pollack MM, Banks R, Holubkov R, et al. Long-Term Outcome of PICU Patients Discharged With New, Functional Status Morbidity. Pediatr Crit Care Med 2021;22:27-39.

14. Matsumoto $\mathrm{N}$, Hatachi T, Inata $\mathrm{Y}$, et al. Long-term mortality and functional outcome after prolonged paediatric intensive care unit stay. Eur J Pediatr 2019;178:155-60.

15. Woodruff AG, Choong K. Long-Term Outcomes and the Post-Intensive Care Syndrome in Critically Ill Children: A North American Perspective. Children (Basel) 2021;8:254.

16. Aspesberro F, Mangione-Smith R, Zimmerman JJ. Healthrelated quality of life following pediatric critical illness. Intensive Care Med 2015;41:1235-46.

17. Herrup EA, Wieczorek B, Kudchadkar SR. Characteristics of postintensive care syndrome in survivors of pediatric critical illness: A systematic review. World J Crit Care Med 2017;6:124-34.

18. Nelson LP, Gold JI. Posttraumatic stress disorder in children and their parents following admission to the pediatric intensive care unit: a review. Pediatr Crit Care Med 2012;13:338-47.

19. Als LC, Nadel S, Cooper M, et al. Neuropsychologic function three to six months following admission to the PICU with meningoencephalitis, sepsis, and other disorders: a prospective study of school-aged children. Crit Care Med 2013;41:1094-103. 
20. Baker SC, Gledhill JA. Systematic Review of Interventions to Reduce Psychiatric Morbidity in Parents and Children After PICU Admissions. Pediatr Crit Care Med 2017;18:343-8.

21. Fink EL, Watson RS. PICS-p: It Is About Time (and Family)! But How Did Adult Medicine Beat Pediatrics to a Holistic View of the Patient? Pediatr Crit Care Med 2018;19:375-7.

22. Manning JC, Pinto NP, Rennick JE, et al. Conceptualizing Post Intensive Care Syndrome in Children-The PICS-p Framework. Pediatr Crit Care Med 2018;19:298-300.

23. Fink EL, Tasker RC. Brain-related outcome measures in trials recruiting critically-ill children. Curr Opin Pediatr 2019;31:775-82.

24. Geense WW, van den Boogaard M, van der Hoeven JG, et al. Nonpharmacologic Interventions to Prevent or Mitigate Adverse Long-Term Outcomes Among ICU Survivors: A Systematic Review and Meta-Analysis. Crit Care Med 2019;47:1607-18.

25. Lopes-Júnior LC, Rosa MADRP, Lima RAG. Psychological and Psychiatric Outcomes Following PICU Admission: A Systematic Review of Cohort Studies. Pediatr Crit Care Med 2018;19:e58-67.

26. Curley MA, Wypij D, Watson RS, et al. Protocolized sedation vs usual care in pediatric patients mechanically ventilated for acute respiratory failure: a randomized clinical trial. JAMA 2015;313:379-89.

27. Schlapbach LJ, Horton SB, Long DA, et al. Study protocol: NITric oxide during cardiopulmonary bypass to improve Recovery in Infants with Congenital heart defects (NITRIC trial): a randomised controlled trial. BMJ Open 2019;9:e026664.

28. van Zellem L, Utens EM, de Wildt SN, et al. Analgesiasedation in PICU and neurological outcome: a secondary analysis of long-term neuropsychological follow-up in meningococcal septic shock survivors*. Pediatr Crit Care Med 2014;15:189-96.

29. Güiza F, Vanhorebeek I, Verstraete S, et al. Effect of early parenteral nutrition during paediatric critical illness on DNA methylation as a potential mediator of impaired neurocognitive development: a pre-planned secondary analysis of the PEPaNIC international randomised controlled trial. Lancet Respir Med 2020;8:288-303.

30. Brown SM, Bose S, Banner-Goodspeed V, et al. Approaches to Addressing Post-Intensive Care Syndrome among Intensive Care Unit Survivors. A Narrative Review. Ann Am Thorac Soc 2019;16:947-56.

31. Fink EL, Maddux AB, Pinto N, et al. A Core Outcome Set for Pediatric Critical Care. Crit Care Med 2020;48:1819-28.

32. Dorling JS, Field DJ. Follow up of infants following discharge from the neonatal unit: structure and process. Early Hum Dev 2006;82:151-6.

33. Doyle LW, Anderson PJ, Battin M, et al. Long term follow up of high risk children: who, why and how? BMC Pediatr 2014;14:279.

34. Pavoni V, Pazzi M, Manni A, et al. The Post-ICU Patient. ICU Management \& Practice 2020;20:293-6.

35. Tume LN, Menzies JC, Ray S, et al. Research Priorities for U.K. Pediatric Critical Care in 2019: Healthcare Professionals' and Parents' Perspectives. Pediatr Crit Care Med 2021;22:e294-e301.

36. Raman S, Brown G, Long D, et al. Priorities for Pediatric Critical Care Research - a Modified Delphi Study by the Australian and New Zealand Intensive Care Society, Paediatric Study Group. Crit Care Resusc 2021;23:194-201.

37. Fayed N, Cameron S, Fraser D, et al. Priority Outcomes in Critically Ill Children: A Patient and Parent Perspective. Am J Crit Care 2020;29:e94-e103.

38. Fink EL, Jarvis JM, Maddux AB, et al. Development of a core outcome set for pediatric critical care outcomes research. Contemp Clin Trials 2020;91:105968.

39. Merritt C, Menon K, Agus MSD, et al. Beyond Survival: Pediatric Critical Care Interventional Trial Outcome Measure Preferences of Families and Healthcare Professionals. Pediatr Crit Care Med 2018;19:e105-11.

40. Rodriguez A, Smith J, Barrett D. Research made simple: developing complex interventions. Evid Based Nurs 2020;23:35-7.

41. Ali SS. A brief review of risk-factors for growth and developmental delay among preschool children in developing countries. Adv Biomed Res 2013;2:91.

42. Hertzman C, Wiens M. Child development and long-term outcomes: a population health perspective and summary of successful interventions. Soc Sci Med 1996;43:1083-95.

43. Marino BS, Lipkin PH, Newburger JW, et al. Neurodevelopmental outcomes in children with congenital heart disease: evaluation and management: a scientific statement from the American Heart Association. Circulation 2012;126:1143-72.

44. Long D, Minogue J, Hamblin S, et al. Neurodevelopmental and Sociemotional Outcome and Quality of Life in Children admitted to the Paediatric Intensive Care Unit: A Retrospective Study. Paediatric Critical Care Medicine 2021;22:24-5.

45. Rollins CK, Newburger JW, Roberts AE. Genetic contribution to neurodevelopmental outcomes in 
congenital heart disease: are some patients predetermined to have developmental delay? Curr Opin Pediatr 2017;29:529-33.

46. Watson RS, Asaro LA, Hertzog JH, et al. Long-Term Outcomes after Protocolized Sedation versus Usual Care in Ventilated Pediatric Patients. Am J Respir Crit Care Med 2018;197:1457-67.

47. Zimmerman JJ, Banks R, Berg RA, et al. Trajectory of Mortality and Health-Related Quality of Life Morbidity Following Community-Acquired Pediatric Septic Shock. Crit Care Med 2020;48:329-37.

48. Als LC, Picouto MD, Hau SM, et al. Mental and physical well-being following admission to pediatric intensive care. Pediatr Crit Care Med 2015;16:e141-9.

49. Niemi MEK, Martin HC, Rice DL, et al. Common genetic variants contribute to risk of rare severe neurodevelopmental disorders. Nature 2018;562:268-71.

50. Goff DA, Luan X, Gerdes M, et al. Younger gestational age is associated with worse neurodevelopmental outcomes after cardiac surgery in infancy. J Thorac Cardiovasc Surg 2012;143:535-42.

51. Anderson V, Catroppa C, Morse S, et al. Functional plasticity or vulnerability after early brain injury? Pediatrics 2005;116:1374-82.

52. Ong C, Lee JH, Leow MK, et al. Functional Outcomes and Physical Impairments in Pediatric Critical Care Survivors: A Scoping Review. Pediatr Crit Care Med 2016;17:e247-59.

53. Meert KL, Reeder R, Maddux AB, et al. Trajectories and Risk Factors for Altered Physical and Psychosocial HealthRelated Quality of Life After Pediatric CommunityAcquired Septic Shock. Pediatr Crit Care Med 2020;21:869-78.

54. Slomine BS, Silverstein FS, Christensen JR, et al. Neurobehavioral Outcomes in Children After Out-ofHospital Cardiac Arrest. Pediatrics 2016;137:e20153412.

55. Killien EY, Farris RWD, Watson RS, et al. Health-Related Quality of Life Among Survivors of Pediatric Sepsis. Pediatr Crit Care Med 2019;20:501-9.

56. Mitchell WG, Deane A, Brown A, et al. Long term outcomes for Aboriginal and Torres Strait Islander Australians after hospital intensive care. Med J Aust 2020;213:16-21.

57. Ostrowski JA, MacLaren G, Alexander J, et al. The burden of invasive infections in critically ill Indigenous children in Australia. Med J Aust 2017;206:78-84.

58. Laupland KB, Karmali S, Kirkpatrick AW, et al. Distribution and determinants of critical illness among status Aboriginal Canadians. A population-based assessment. J Crit Care 2006;21:243-7.

59. Barnato AE, Alexander SL, Linde-Zwirble WT, et al. Racial variation in the incidence, care, and outcomes of severe sepsis: analysis of population, patient, and hospital characteristics. Am J Respir Crit Care Med 2008;177:279-84.

60. Sze S, Pan D, Nevill CR, et al. Ethnicity and clinical outcomes in COVID-19: A systematic review and metaanalysis. EClinicalMedicine 2020;29:100630.

61. Leimanis Laurens M, Snyder K, Davis AT, et al. Racial/ Ethnic Minority Children With Cancer Experience Higher Mortality on Admission to the ICU in the United States. Pediatr Crit Care Med 2020;21:859-68.

62. Ruan S, Abdel-Latif ME, Bajuk B, et al. The associations between ethnicity and outcomes of infants in neonatal intensive care units. Arch Dis Child Fetal Neonatal Ed 2012;97:F133-8.

63. Brosig CL, Bear L, Allen S, et al. Preschool Neurodevelopmental Outcomes in Children with Congenital Heart Disease. J Pediatr 2017;183:80-86.e1.

64. Gaynor JW, Stopp C, Wypij D, et al. Neurodevelopmental outcomes after cardiac surgery in infancy. Pediatrics 2015;135:816-25.

65. Patra K, Greene MM, Patel AL, et al. Maternal Education Level Predicts Cognitive, Language, and Motor Outcome in Preterm Infants in the Second Year of Life. Am J Perinatol 2016;33:738-44.

66. Nelson LP, Lachman SE, Li SW, et al. The Effects of Family Functioning on the Development of Posttraumatic Stress in Children and Their Parents Following Admission to the PICU. Pediatr Crit Care Med 2019;20:e208-15.

67. Small L, Melnyk BM. Early predictors of post-hospital adjustment problems in critically ill young children. Res Nurs Health 2006;29:622-35.

68. Slain KN, Shein SL, Stormorken AG, et al. Outcomes of Children With Critical Bronchiolitis Living in Poor Communities. Clin Pediatr (Phila) 2018;57:1027-32.

69. Andrist E, Riley CL, Brokamp C, et al. Neighborhood Poverty and Pediatric Intensive Care Use. Pediatrics 2019;144:e20190748.

70. Stremler R, Haddad S, Pullenayegum E, et al. Psychological Outcomes in Parents of Critically Ill Hospitalized Children. J Pediatr Nurs 2017;34:36-43.

71. Keenan HT, Hooper SR, Wetherington CE, et al. Neurodevelopmental consequences of early traumatic brain injury in 3-year-old children. Pediatrics 2007;119:e616-23.

72. Cheung C, La Count S, Jarvis J, et al. 806: Prevalence of Adverse Social Determinants of Health in Families of 
Children With Critical Illness. Critical Care Medicine 2021;49:399.

73. Kachmar AG, Irving SY, Connolly CA, et al. A Systematic Review of Risk Factors Associated With Cognitive Impairment After Pediatric Critical Illness. Pediatr Crit Care Med 2018;19:e164-71.

74. Bradley RH, Corwyn RF. Socioeconomic status and child development. Annu Rev Psychol 2002;53:371-99.

75. Kachmar AG, Connolly CA, Wolf S, et al. Socioeconomic Status in Pediatric Health Research: A Scoping Review. J Pediatr 2019;213:163-70.

76. Judge D, Nadel S, Vergnaud S, et al. Psychiatric adjustment following meningococcal disease treated on a PICU. Intensive Care Med 2002;28:648-50.

77. Garralda ME, Gledhill J, Nadel S, et al. Longerterm psychiatric adjustment of children and parents after meningococcal disease. Pediatr Crit Care Med 2009; 10:675-80.

78. Darling SJ, Hearps SJC, Muscara F, et al. Psychological trajectories of mothers and fathers following their child's diagnosis of a life-threatening illness or injury: A longitudinal investigation. J Clin Psychol 2019;75:1930-42.

79. Balluffi A, Kassam-Adams N, Kazak A, et al. Traumatic stress in parents of children admitted to the pediatric intensive care unit. Pediatr Crit Care Med 2004;5:547-53.

80. Watson RS, Asaro LA, Hutchins L, et al. Risk Factors for Functional Decline and Impaired Quality of Life after Pediatric Respiratory Failure. Am J Respir Crit Care Med 2019;200:900-9.

81. Shein SL, Roth E, Pace E, et al. Long-Term Neurodevelopmental and Functional Outcomes of Normally Developing Children Requiring PICU Care for Bronchiolitis. Journal of Pediatric Intensive Care 2020. Doi: $10.1055 / \mathrm{s}-0040-1716856$.

82. Verstraete S, Verbruggen SC, Hordijk JA, et al. Long-term developmental effects of withholding parenteral nutrition for 1 week in the paediatric intensive care unit: a 2-year follow-up of the PEPaNIC international, randomised, controlled trial. Lancet Respir Med 2019;7:141-53.

83. Jacobs A, Dulfer K, Eveleens RD, et al. Long-term developmental effect of withholding parenteral nutrition in paediatric intensive care units: a 4-year follow-up of the PEPaNIC randomised controlled trial. Lancet Child Adolesc Health 2020;4:503-14.

84. Jacobs A, Dulfer K, Eveleens RD, et al. Long-term developmental effect of withholding parenteral nutrition in paediatric intensive care units: a 4-year follow-up of the PEPaNIC randomised controlled trial. Lancet Child
Adolesc Health 2020;4:503-14.

85. Rennick JE, Morin I, Kim D, et al. Identifying children at high risk for psychological sequelae after pediatric intensive care unit hospitalization. Pediatr Crit Care Med 2004;5:358-63.

86. Smith HAB, Gangopadhyay M, Goben CM, et al. Delirium and Benzodiazepines Associated With Prolonged ICU Stay in Critically Ill Infants and Young Children. Crit Care Med 2017;45:1427-35.

87. Mody K, Kaur S, Mauer EA, et al. Benzodiazepines and Development of Delirium in Critically Ill Children: Estimating the Causal Effect. Crit Care Med 2018;46:1486-91.

88. Bateman RM, Sharpe MD, Jagger JE, et al. 36th International Symposium on Intensive Care and Emergency Medicine: Brussels, Belgium. 15-18 March 2016. Crit Care 2016;20:94. Erratum in: Crit Care 2016;20:347.

89. Dervan LA, Di Gennaro JL, Farris RWD, et al. Delirium in a Tertiary PICU: Risk Factors and Outcomes. Pediatr Crit Care Med 2020;21:21-32.

90. Traube C, Silver G, Reeder RW, et al. Delirium in Critically Ill Children: An International Point Prevalence Study. Crit Care Med 2017;45:584-90.

91. Paterson R. Evaluating delirium in the Paediatric Intensive Care Unit: understanding the acute and long-term impact on child functioning. The University of Queensland; 2019.

92. Silver G, Doyle H, Hegel E, et al. Association Between Pediatric Delirium and Quality of Life After Discharge. Crit Care Med 2020;48:1829-34.

93. Kok L, Slooter AJ, Hillegers MH, et al. Benzodiazepine Use and Neuropsychiatric Outcomes in the ICU: A Systematic Review. Crit Care Med 2018;46:1673-80.

94. Girard TD, Shintani AK, Jackson JC, et al. Risk factors for post-traumatic stress disorder symptoms following critical illness requiring mechanical ventilation: a prospective cohort study. Crit Care 2007;11:R28.

95. Long D, Gibbons K, Le Brocque R, et al. Midazolam Exposure in the Paediatric Intensive Care Unit predicts acute Posttraumatic Stress Symptoms in Children. Australian Critical Care 2021. Doi: 10.1016/ j.aucc.2021.06.004.

96. Cortes AM, Saltzman KM, Weems CF, et al. Development of anxiety disorders in a traumatized pediatric population: a preliminary longitudinal evaluation. Child Abuse Negl 2005;29:905-14.

97. De Young AC, Kenardy JA, Cobham VE, et al. Prevalence, comorbidity and course of trauma reactions in young burninjured children. J Child Psychol Psychiatry 2012;53:56-63. 
98. Kocek M, Wilcox R, Crank C, et al. Evaluation of the relationship between opioid exposure in extremely low birth weight infants in the neonatal intensive care unit and neurodevelopmental outcome at 2 years. Early Hum Dev 2016;92:29-32.

99. Guerra GG, Robertson CM, Alton GY, et al. Neurodevelopmental outcome following exposure to sedative and analgesic drugs for complex cardiac surgery in infancy. Paediatr Anaesth 2011;21:932-41.

100. Rozé JC, Denizot S, Carbajal R, et al. Prolonged sedation and/or analgesia and 5-year neurodevelopment outcome in very preterm infants: results from the EPIPAGE cohort. Arch Pediatr Adolesc Med 2008;162:728-33.

101.Iqbal O'Meara AM, Miller Ferguson N, Zven SE, et al. Potential Neurodevelopmental Effects of Pediatric Intensive Care Sedation and Analgesia: Repetitive Benzodiazepine and Opioid Exposure Alters Expression of Glial and Synaptic Proteins in Juvenile Rats. Crit Care Explor 2020;2:e0105.

102.Humphreys KL, King LS, Sacchet MD, et al. Evidence for a sensitive period in the effects of early life stress on hippocampal volume. Dev Sci 2019;22:e12775.

103. Vohr BR, O'Shea M, Wright LL. Longitudinal multicenter follow-up of high-risk infants: why, who, when, and what to assess. Semin Perinatol 2003;27:333-42.

104. Maddux AB, Pinto N, Fink EL, et al. Postdischarge Outcome Domains in Pediatric Critical Care and the Instruments Used to Evaluate Them: A Scoping Review. Crit Care Med 2020;48:e1313-21.

105. Meyer J, Brett SJ, Waldmann C. Should ICU clinicians follow patients after ICU discharge? Yes. Intensive Care Med 2018;44:1539-41.

106. Sevin CM, Jackson JC. Post-ICU Clinics Should Be Staffed by ICU Clinicians. Crit Care Med 2019;47:268-72.

107. Vijayaraghavan BKT, Willaert X, Cuthbertson BH. Should ICU clinicians follow patients after ICU discharge? No. Intensive Care Med 2018;44:1542-4.

108. Chorna O, Baldwin HS, Neumaier J, et al. Feasibility of a Team Approach to Complex Congenital Heart Defect Neurodevelopmental Follow-Up: Early Experience of a Combined Cardiology/Neonatal Intensive Care Unit Follow-Up Program. Circ Cardiovasc Qual Outcomes 2016;9:432-40.

109.Eagleson K, Campbell M, McAlinden B, et al. Congenital Heart Disease Long-term Improvement in Functional hEalth (CHD LIFE): A partnership programme to improve the long-term functional health of children with congenital heart disease in Queensland. J Paediatr Child
Health 2020;56:1003-9.

110.Dodd JN, Hall TA, Guilliams K, et al. Optimizing Neurocritical Care Follow-Up Through the Integration of Neuropsychology. Pediatr Neurol 2018;89:58-62.

111. Andrews B, Rahman N, Pinto N. Family Support and ICU Survivorship: Lessons Learned from the Pediatric Critical Care Experience. In: Netzer G. editors. Families in the Intensive Care Unit. Cham: Springer, 2018; 101-18.

112. Weitzman C, Wegner L; Section on Developmental and Behavioral Pediatrics, et al. Promoting optimal development: screening for behavioral and emotional problems. Pediatrics 2015;135:384-95.

113.Jeyendra A, Rajadurai J, Chanmugam J, et al. Australian general practitioners' perspectives on their role in wellchild health care. BMC Fam Pract 2013;14:2.

114. Wood R, Wilson P. General practitioner provision of preventive child health care: analysis of routine consultation data. BMC Fam Pract 2012;13:73.

115. Harrison M, Jones P, Sharif I, et al. General PediatricianStaffed Behavioral/Developmental Access Clinic Decreases Time to Evaluation of Early Childhood Developmental Disorders. J Dev Behav Pediatr 2017;38:353-7.

116. Oberklaid F, Efron D. Developmental delay--identification and management. Aust Fam Physician 2005;34:739-42.

117.Pedersen KM, Andersen JS, Søndergaard J. General practice and primary health care in Denmark. J Am Board Fam Med 2012;25 Suppl 1:S34-8.

118. Developmental surveillance and screening of infants and young children. Pediatrics 2001;108:192-6.

119. Fishbane M, Starfield B. Child health care in the United States: a comparison of pediatricians and general practitioners. N Engl J Med 1981;305:552-6.

120.Schmied V, Mills A, Kruske S, et al. The nature and impact of collaboration and integrated service delivery for pregnant women, children and families. J Clin Nurs 2010;19:3516-26.

121. Ducassou S, Chipi M, Pouyade A, et al. Impact of shared care program in follow-up of childhood cancer survivors: An intervention study. Pediatr Blood Cancer 2017;64:e26541.

122. Antonelli RC, McAllister JW, Popp J. Making care coordination a critical component of the pediatric health system: a multidisciplinary framework. 2009. Available online: https://www.commonwealthfund.org/sites/default/ files/documents/__media_files_publications_fund_ report_2009_may_making_care_coordination_a_critical_ component_1277_antonelli_making_care_coordination_ critical_final.pdf 
123. Kuethe M, Vaessen-Verberne A, Mulder P, et al. Paediatric asthma outpatient care by asthma nurse, paediatrician or general practitioner: randomised controlled trial with twoyear follow-up. Prim Care Respir J 2011;20:84-91.

124.McMurray A, Ward L, Johnston K, et al. The primary health care nurse of the future: Preliminary evaluation of the Nurse Navigator role in integrated care. Collegian 2018;25:517-24.

125. Ferguson NM, Lively L, Sullivan T, et al. 805: Inpatient Nurse Navigator Improves Communication and FollowUp After Pediatric TBI Admission. Critical Care Medicine 2021;49:399.

126. Williams TA, Leslie GD. Beyond the walls: a review of ICU clinics and their impact on patient outcomes after leaving hospital. Aust Crit Care 2008;21:6-17.

127. Stone KP, Woodward GA. Pediatric patients in the adult Trauma Bay-comfort level and challenges. Clinical Pediatric Emergency Medicine 2010;11:48-56.

128. Pollack MM, Alexander SR, Clarke N, et al. Improved outcomes from tertiary center pediatric intensive care: a statewide comparison of tertiary and nontertiary care facilities. Crit Care Med 1991;19:150-9.

129. Mayer KP, Boustany H, Cassity EP, et al. ICU Recovery Clinic Attendance, Attrition, and Patient Outcomes: The Impact of Severity of Illness, Gender, and Rurality. Crit Care Explor 2020;2:e0206.

130.Jackson BJ, Needelman H. Building a system of child find through a 3-tiered model of follow-up. Infants \& Young Children 2007;20:255-65.

131.Landier W, Skinner R, Wallace WH, et al. Surveillance for Late Effects in Childhood Cancer Survivors. J Clin Oncol 2018;36:2216-22.

132. Bakhru RN, Davidson JF, Bookstaver RE, et al. Implementation of an ICU Recovery Clinic at a Tertiary Care Academic Center. Crit Care Explor 2019;1:e034.

133. Martillo MA, Dangayach NS, Tabacof L, et al. Postintensive Care Syndrome in Survivors of Critical Illness Related to Coronavirus Disease 2019: Cohort Study From a New York City Critical Care Recovery Clinic. Crit Care Med 2021;49:1427-38.

134. Sevin CM, Bloom SL, Jackson JC, et al. Comprehensive care of ICU survivors: Development and implementation of an ICU recovery center. J Crit Care 2018;46:141-8.

135. Cook K, Bartholdy R, Raven M, et al. A national survey of intensive care follow-up clinics in Australia. Aust Crit Care 2020;33:533-7.

136. Prevedello DH, Preiser JC. Feasibility of Follow-Up Consultations. In: Preiser JC, Herridge M, Azoulay E. editors. Post-Intensive Care Syndrome. Lessons from the ICU (Under the Auspices of the European Society of Intensive Care Medicine). Cham: Springer, 2020; 331-42. 137. Haines KJ, McPeake J, Hibbert E, et al. Enablers and Barriers to Implementing ICU Follow-Up Clinics and Peer Support Groups Following Critical Illness: The Thrive Collaboratives. Crit Care Med 2019;47:1194-200.

138. Jalilian L, Cannesson M, Kamdar N. Post-ICU Recovery Clinics in the Era of Digital Health and Telehealth. Crit Care Med 2019;47:e796-7.

139. Gluck S, Chapple LS, Chapman MJ, et al. A scoping review of use of wearable devices to evaluate outcomes in survivors of critical illness. Crit Care Resusc 2017;19:197-204.

140. Hodalova S, Moore S, Dowds J, et al. Feasibility of Telephone Follow-Up after Critical Care Discharge. Med Sci (Basel) 2020;8:16.

141. Gildea MR, Moler FW, Page K, et al. Methods Used to Maximize Follow-Up: Lessons Learned From the Therapeutic Hypothermia After Pediatric Cardiac Arrest Trials. Pediatr Crit Care Med 2020;21:4-11.

142. Fitzgerald JC, Kelly NA, Hickey C, et al. Implementation of a Follow-Up System for Pediatric Sepsis Survivors in a Large Academic Pediatric Intensive Care Unit. Front Pediatr 2021;9:691692.

143. Health Quality Ontario . Effect of Early Follow-Up After Hospital Discharge on Outcomes in Patients With Heart Failure or Chronic Obstructive Pulmonary Disease: A Systematic Review. Ont Health Technol Assess Ser 2017;17:1-37.

144. Williams TA, Leslie GD. Challenges and possible solutions for long-term follow-up of patients surviving critical illness. Aust Crit Care 2011;24:175-85.

145. Andrews B, Pinto N. Optimizing Discharge from Intensive Care and Follow-Up Strategies for Pediatric Patients. J Pediatr 2019;205:8-9.

146. Teague S, Youssef GJ, Macdonald JA, et al. Retention strategies in longitudinal cohort studies: a systematic review and meta-analysis. BMC Med Res Methodol 2018;18:151.

147.Abshire M, Dinglas VD, Cajita MI, et al. Participant retention practices in longitudinal clinical research studies with high retention rates. BMC Med Res Methodol 2017;17:30.

148. Robinson KA, Dennison CR, Wayman DM, et al. Systematic review identifies number of strategies important for retaining study participants. J Clin Epidemiol 2007;60:757-65.

149. Davies H, McKenzie N, Williams TA, et al. Challenges during long-term follow-up of ICU patients with and 
without chronic disease. Aust Crit Care 2016;29:27-34.

150. Booker CL, Harding S, Benzeval M. A systematic review of the effect of retention methods in population-based cohort studies. BMC Public Health 2011;11:249.

151.L Orton J, McGinley JL, Fox LM, et al. Challenges of neurodevelopmental follow-up for extremely preterm infants at two years. Early Hum Dev 2015;91:689-94.

152. Bonevski B, Randell M, Paul C, et al. Reaching the hardto-reach: a systematic review of strategies for improving health and medical research with socially disadvantaged groups. BMC Med Res Methodol 2014;14:42.

153.Wilcox ME, Ely EW. Challenges in conducting long-term outcomes studies in critical care. Curr Opin Crit Care 2019;25:473-88.

154. Curley MAQ, Watson RS. After PICU. Supporting children and families after a critical illness. Available online: www.afterpicu.com

155.Brigham and Women's Hospital. After the ICU. Available online: www.aftertheicu.org

156. Bench S, Cornish J, Xyrichis A. Intensive care discharge summaries for general practice staff: a focus group study. Br J Gen Pract 2016;66:e904-12.

157.Daruwalla F, Lamb F, Mearns C. Quality and value of intensive care discharge summaries for general practitioners. Critical Care 2012;16:1-189.

158. Van Der Schaaf M, Bakhshi-Raiez F, Van Der Steen M, et al. Recommendations for intensive care follow-up clinics; report from a survey and conference of Dutch intensive cares. Minerva Anestesiol 2015;81:135-44.

159. Potharst ES, Houtzager BA, van Sonderen L, et al. Prediction of cognitive abilities at the age of 5 years using developmental follow-up assessments at the age of 2 and 3 years in very preterm children. Dev Med Child Neurol 2012;54:240-6.

160.Ijsselstijn H, van Heijst AF. Long-term outcome of children treated with neonatal extracorporeal membrane oxygenation: increasing problems with increasing age. Semin Perinatol 2014;38:114-21.

161. Church P, Luther M, Asztalos E. The perfect storm: the high prevalence low severity outcomes of the Preterm Survivors. Current Pediatric Reviews 2012;8:142-51.

162. Killien EY, Watson RS, Zimmerman JJ. Inherent value of baseline measures when assessing the trajectory of healthrelated quality of life among children surviving critical illness. Intensive Care Med 2018;44:1979-81.

163. American Academy of Pediatrics. Follow-up care of highrisk infants. Pediatrics 2004;114:1377-97.
164. Scholefield BR, Martin J, Penny-Thomas K, et al. NEUROlogical Prognosis After Cardiac Arrest in Kids (NEUROPACK) study: protocol for a prospective multicentre clinical prediction model derivation and validation study in children after cardiac arrest. BMJ Open 2020;10:e037517.

165. Rennick JE, Dougherty G, Chambers C, et al. Children's psychological and behavioral responses following pediatric intensive care unit hospitalization: the caring intensively study. BMC Pediatr 2014;14:276.

166. Morton K, Darlington AE, Marino LV. Protocol for a multicentre longitudinal mixed-methods study: feeding and survivorship outcomes in previously healthy young paediatric Intensive care survivors (the PIES Study). BMJ Open 2020;10:e041234.

167. Manning JC, Latour JM, Curley MAQ, et al. Study protocol for a multicentre longitudinal mixed methods study to explore the Outcomes of ChildrEn and fAmilies in the first year after paediatric Intensive Care: the OCEANIC study. BMJ Open 2020;10:e038974.

168. Poh PF, Lee JH. Singapore's Health Outcomes After Critical Illness in Kids (SHACK). U.S. National Library of Medicine. 2020. Available online: https://clinicaltrials.gov/ ct2/show/NCT04637113

169. Du Pont-Thibodeau G, La KA, Francois T, et al. 367: Outcomes after pediatric intensive care: first-year experience of a PICU follow-up clinic. Critical Care Medicine 2020;48:165.

170.Samuel VM, Colville GA, Goodwin S, et al. The Value of Screening Parents for Their Risk of Developing Psychological Symptoms After PICU: A Feasibility Study Evaluating a Pediatric Intensive Care Follow-Up Clinic. Pediatr Crit Care Med 2015;16:808-13.

171. Williams CN, Kirby A, Piantino J. If You Build It, They Will Come: Initial Experience with a Multi-Disciplinary Pediatric Neurocritical Care Follow-Up Clinic. Children (Basel) 2017;4:83.

172. Hickey E, Hoehn S. 1215: Stumbling blocks and successes in starting a PICU follow-up clinic in an academic medical center. Critical Care Medicine 2020;48:585.

Cite this article as: Long DA, Fink EL. Transitions from short to long-term outcomes in pediatric critical care: considerations for clinical practice. Transl Pediatr 2021;10(10):2858-2874. doi: 10.21037/tp-21-61 